\title{
OPTIMASI MODEL PENGIRIMAN BANTUAN BENCANA GEMPA BUMI DI BPBD KABUPATEN BANTUL
}

\author{
${ }^{1}$ Yohanes Anton Nugroho \\ ${ }^{1}$ Program Studi Teknik Industri, Fakultas Sains dan Teknologi, Universitas Teknologi Yogyakarta \\ Jl. Glagahsari No. 63, Yogyakarta \\ e-mail: yohanesanton@uty.ac.id
}

\begin{abstract}
Bantul regency had experienced the disasters caused by the earthquake occurred in Bantul in 2006. 4121 residents of Bantul region died, thousands of buildings was collapsed and many damages in many places. This paper develops a model of earthquake damage and analyzes distributing humanitarian aid from BPBD Bantul to each warehouse distributor in each district that classified as Vehicle Routing Problem With Time Window (VRPTW). This solution model is developed using Linear Programming and The Nearest Neighbors Algorithm s Algorithm. The goal of those methods is expected to get a distribution solution more fast and efficient. Based on modeling result using scenario of refugee number $80 \%$ from population in very vulnerable area, $60 \%$ in vulnerable area, and $40 \%$ in less vulnerable area obtained mathematical model of allocation distribution done by optimization with Linear Programming, which obtained distribution allocation solution using 16 medium trucks and 4 heavy trucks only need 3 days.
\end{abstract}

Key words : Vehicle Routing Problem; Linear Programming; Nearest Neighbors Algorithm s Algorithm; Humanitarian Aid

\section{PENDAHULUAN}

Gempa bumi 27 Mei 2006 di kabupaten Bantul menyebabkan 4121 orang meninggal dunia dan ribuan keluarga harus mengungsi. Beberapa masalah yang timbul terkait dengan adanya permasalahan di dalam pendistribusian bantuan di kabupaten Bantul menurut Susetiono (2010), adalah keterlambatan pemenuhan kebutuhan pangan dan kesehatan bagi korban, bantuan tidak sesuai dengan kebutuhan baik dalam jumlah maupun jenis, kurangnya SDM untuk pendistribusian bantuan pangan dan kesehatan, serta biaya operasional untuk pendistribusian bantuan pangan dan kesehatan yang minim.

Badan Penanggulangan Bencana Daerah (BPBD) kabupaten Bantul memiliki kewenangan mendistribusikan bantuan kemanusiaan apabila terjadi bencana. Permasalahan dalam pendistribusian bantuan di BPBD kabupaten Bantul adalah keterbatasan jumlah kendaraan, jumlah pasokan dan luasnya wilayah, sementara penyampaian bantuan kepada masyarakat perlu segera disampaikan. Berdasarkan pertimbangan tersebut, maka diperlukan suatu rencana distribusi yang efektif dan efisien.

Permasalah distribusi bantuan di BPBD kabupaten Bantul dapat dikategorikan sebagai Vehicle Routing Problem Time Window (VRPTW). Model VRPTW digunakan untuk mencari rute pengiriman tercepat, dengan waktu terbatas. Beberapa penelitian terkait masalah VRPTW dalam pendistribusian diantaranya diteliti oleh Alonso et al (2008), Kritikos dan Ioannou (2010), El-Sherbeny (2010), Boonsam et al (2012), Palit dan Selly (2012), Cahya (2013), Liu (2013), dan Mukhsinin (2013).

Pemilihan metode Nearest Neighbors Algorithm s Algorithm dalam penentuan rute pengiriman didasarkan pada beberapa peneliti yang sebelumnya, diantaranya Boonsam et al (2012), Mukhsinin (2013), Akhbari et al (2014), dan Suhaibah (2016). Metode Nearest Neighbors Algorithm digunakan karena mampu untuk membantu mengidentifikasikan rute kendaraan dan menyusun strategi pada kelompok sasaran.

Pada penekitian ini dikembangkan suatu model distribusi bantuan yang efektif dan efisien. Pengembangan model didasarkan pada perkiraan jumlah pengungsi sebesar $80 \%$ dari populasi pada daerah dengan tingkat kerawanan sangat rawan, $60 \%$ pada daerah dengan tingkat rawan dan $40 \%$ pada tingkat kurang rawan. Penentuan tingkat kerawanan terhadap bencana gempa bumi didasarkan pada peta mikrozonasi yang digunakan BPBD kabupaten Bantul, dimana ditunjukkan bahwa terdapat 6 wilayah kecamatan dengan tingkat sangat rawan (kecamatan 
Sanden, Kretek, Jetis, Imogiri, Piyungan dan Banguntapan), 8 kecamatan dengan tingkat rawan (kecamatan Pundong, Bambanglipuro, Pandak, Bantul, Pleret, Sewon, Pajangan, Sedayu), dan 3 kecamatan dengan tingkat kurang rawan (kecamatan Srandakan, Dlingo, dan Kasihan).

\section{METODE PENELITIAN}

\section{Emergency Logistic}

Logistik secara umum adalah proses merencanakan, menerapkan, dan mengendalikan aliran, barang dan jasa yang efisien, efektif, dan informasi terkait dari titik asal hingga titik konsumsi untuk tujuan memenuhi persyaratan pelanggan dengan total biaya terendah (Cooper $e t$ al, 1997). Sementara logistik kondisi darurat atau bencana menurut Sheu (2007) dapat didefinisikan sebagai proses perencanaan, pengelolaan dan pengendalian arus bantuan, informasi, dan layanan yang efisien dari titik asal ke titik tujuan untuk memenuhi kebutuhan mendesak dari orang-orang yang terkena dampak dalam kondisi darurat.

Menurut Timoleon (2012), aktivitas logistik untuk bisnis dan logistik kondisi darurat (emergency logistic) atau logistik bencana secara umum memiliki aktivitas yang hampir sama. Hanya saja aktivitas logistik untuk bencana memiliki beberapa tantangan, diantaranya adalah ketidakpasitian (rute, keamanan, kapasitas, permintaan), akses komunikasi dan koordinasi yang rumit, dan sumber daya yang terbatas. Semua logistik untuk bencana dan kondisi darurat harus dirancang sedemikian rupa, sehingga proses penyampian barang dapat tepat tujuan dan tepat waktu. Agar lebih memahami keputusan dan prioritas yang dibuat dalam operasi yang berkaitan dengan logistik kemanusiaan, kita perlu menilai karakteristik utama dari rantai pasokan kemanusiaan dibandingkan dengan rekan komersial.

\section{Nearest Neighbors Algorithm}

Algoritma Nearest Neighbors akan melakukan pencarian tujuan pengiriman menuju "tetangga" terdekat yang berorientasi waktu. Pada setiap iterasi berikutnya, pencarian heuristik untuk pelanggan yang mendekati pelanggan terakhir ditambahkan ke dalam rute. Rute baru dimulai setiap kali pencarian gagal menemukan tempat penyisipan yang layak, kecuali tidak ada lagi pelanggan yang belum dikunjungi. Metrik yang digunakan untuk penentuan rute mengukur kedekatan setiap pasangan pelanggan mencoba untuk memperhitungkan kedekatan geografis dan waktu pelanggan (Braysy dan Gendreau, 2005).

Cara kerja dari Nearest Neighbors Algorithm menurut Shenoy (2012) adalah:

1. Mengelompokkan tujuan sesuai dengan data awal

2. Berawal dari gudang atau depot, selanjutnya dilakukan pencarian lokasi pelanggan yang belum dikunjungi dan memiliki jarak terpendek dari gudang. sebagai lokasi pertama dari pengiriman.

3. Apabila pengiriman telah dilakukan maka dapat dilanjutkan menuju lokasi lain yang memiliki jarak terdekat dari lokasi sebelumnya, asalkan jumlah pengiriman tidak melebihi kapasitas kendaraan

a. Apabila ada lokasi yang terpilih sebagai lokasi berikutnya dan terdapat sisa kapasitas kendaraan, dilanjutkan ke langkah (b).

b. Bila kendaraan tidak memiliki sisa kapasitas, kembali ke langkah (a).

c. Bila tidak ada lokasi yang terpilih karena jumlah pengiriman melebihi kapasitas kendaraan, maka kembali ke langkah (a). Dimulai lagi dari gudang dan mengunjungi pelanggan yang belum dikunjungi yang memiliki jarak terdekat.

d. Apabila semua lokasi pada kelompok pertama selesai namun waktu dan muatan masih sisa, maka dilanjutkan dengan memilih lokasi pada rute selanjutnya dengan memilih lokasi terdekat terhadap lokasi terakhir pada kelompok pertama hingga waktu atau muatan mendekati kapasitas maksimal, untuk memulai rute selanjutnya dimulai dari depot dilanjutkan seperti langkah (a)

4. Bila semua pelanggan telah dikunjungi tepat satu kali maka algoritma berakhir. 


\section{HASIL DAN PEMBAHASAN}

Pendistribusian paket logistik kemanusiaan dari BPBD dilakukan melalui jalur pemerintahan dari tingkat kabupaten menuju tingkat kecamatan. Kantor BPBD Kabupaten Bantul yang berlokasi di Sumuran, Palbapang, Bantul berada pada koordinat berfungsi sebagai gudang utama. Sementara sebanyak kantor-kantor kecamatan befungsi sebagai gudang penyalur. Gudang-gudang penyalur inilah yang nantinya kan mendistribusikan bantuan ke tingkat posko.

Penerimaan bantuan dari pusat dan BPBD lainnya dilakukan pada kantor BPBD kabupaten Bantul yang berlokasi pada koordinat $7^{\circ} 53^{\prime} 57^{\prime \prime}$ LS 110¹9'18"BT. Bantuan selanjutnya didistribusikan menuju 17 gudang penyalur. Sebanyak 15 gudang penyalur berada pada wilayah dengan ketinggian kurang dari $100 \mathrm{~m}$ dpl, dan 1 gudang penyalur yaitu di kabupaten Dlingo yang harus ditempuh melalui wilayah berketinggian antara 100-499 $\mathrm{m} \mathrm{dpl}$.

Dengan mempertimbangkan jarak, estrimasi pengungsi dan asumsi jumlah paket bantuan yang tersedia sebanyak 60.500 paket/hari serta alat angkut yang tersedia sebanyak 16 truk engkel dan 4 truk tronton, maka didapatkan feasible solution dari Linear Programming untuk distribusi paket bantuan sebesar 3 hari pengiriman (Nugroho et al., 2016). Tabel selanjutnya dapat ditentukan jumlah pengiriman menuju gudang penyalur dapat dilakukan dengan menyang dinyatakan dalam bilangan bulat/integer seperti ditunjukkan Tabel 1.

Tabel 1. Jumlah distribusi paket bantuan (paket)

\begin{tabular}{lccccccc}
\hline \multirow{2}{*}{ Tujuan } & \multirow{2}{*}{ Notasi } & \multicolumn{3}{c}{ Truk Engkel } & \multicolumn{3}{c}{ Truk Tronton } \\
\cline { 2 - 8 } & & $\mathbf{1}$ & $\mathbf{2}$ & $\mathbf{3}$ & $\mathbf{1}$ & $\mathbf{2}$ & $\mathbf{3}$ \\
\hline Srandakan & $\mathrm{j}_{1}$ & & 4000 & & & & \\
Sanden & $\mathrm{j}_{2}$ & & & 8500 & & & \\
Kretek & $\mathrm{j}_{3}$ & & 8000 & & & & \\
Pundong & $\mathrm{j}_{4}$ & & & 6500 & & & \\
Bambanglipuro & $\mathrm{j}_{5}$ & & 7500 & & & & \\
Pandak & $\mathrm{j}_{6}$ & & & 10000 & & & \\
Bantul & $\mathrm{j}_{7}$ & & 11000 & & & & \\
Jetis & $\mathrm{j}_{8}$ & 15500 & & & & & \\
Imogiri & $\mathrm{j}_{9}$ & & & 16500 & & & \\
Dlingo & $\mathrm{j}_{10}$ & & 5000 & & & & \\
Pleret & $\mathrm{j}_{11}$ & & 8000 & & & 20000 \\
Piyungan & $\mathrm{j}_{12}$ & & & & & \\
Banguntapan & $\mathrm{j}_{13}$ & & & 500 & 13000 & 10000 & \\
Sewon & $\mathrm{j}_{14}$ & 12000 & 4000 & & & & \\
Kasihan & $\mathrm{j}_{15}$ & 12500 & & & & & \\
Pajangan & $\mathrm{j}_{16}$ & & & 6000 & & & \\
Sedayu & $\mathrm{j}_{17}$ & 7500 & & 2500 & & & \\
\hline
\end{tabular}

Penentuan rute dilakukan mengikuti jumlah rencana distribusi dan penentuan jenis kendaraan pada Tabel 1. Pengiriman untuk hari pertama adalah mengirimkan bantuan dari gudang utama menuju gudang penyalur di kecamatan Jetis, Sewon, Kasihan dan Sedayu mengunakan truk engkel serta pengiriman menuju kecamatan Banguntapan menggunakan truk trontoh. Pengiriman pada hari kedua adalah mengirimkan bantuan menuju kecamatan Srandakan, Kretek, Bambanglipuro, Bantul, Dlingo, Pleret, dan Sewon menggunakan truk engkel, serta pengiriman menuju Piyungan dan Banguntapan menggunakan truk tronton. Pengiriman pada hari ketiga dilakukan menuju kecamatan Sanden, Pundong, Pandak, Imogiri, Banguntapan, Pajangan dan Sedayu menggunakan truk engkel, serta pengiriman menuju Piyungan menggunakan truk tronton. 
Setelah diketahui hasil penentuan jumlah bantuan yang akan didistribusikan, selanjutnya dilakukan penentuan rute pengiriman menggunakan Nearest Neighbors Algorithm. Hasil dari penentuan rute pengiriman menunjukkan hasil seperti Gambar 1 hingga Gambar 6.

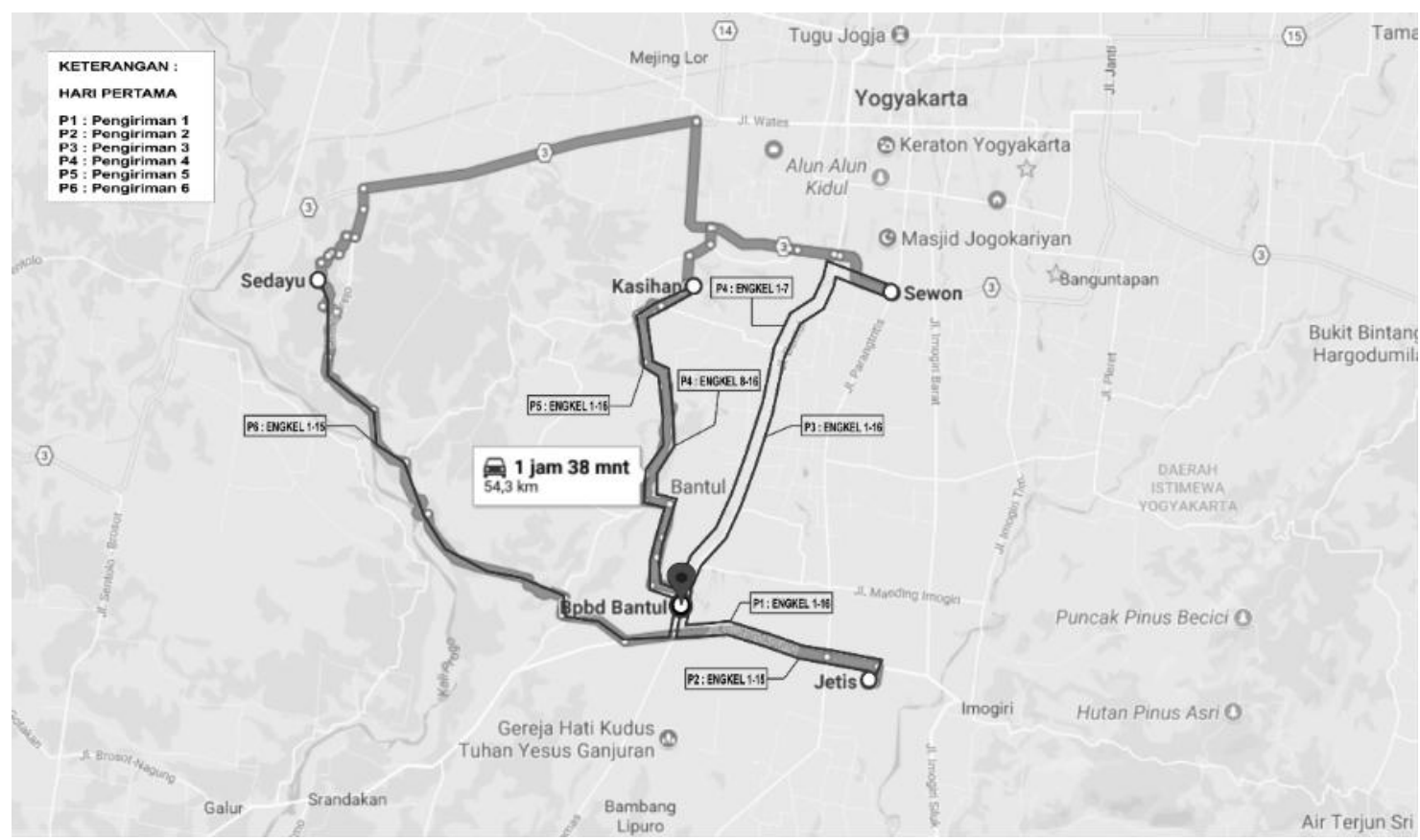

Gambar 1. Rute pengiriman dengan truk engkel hari 1

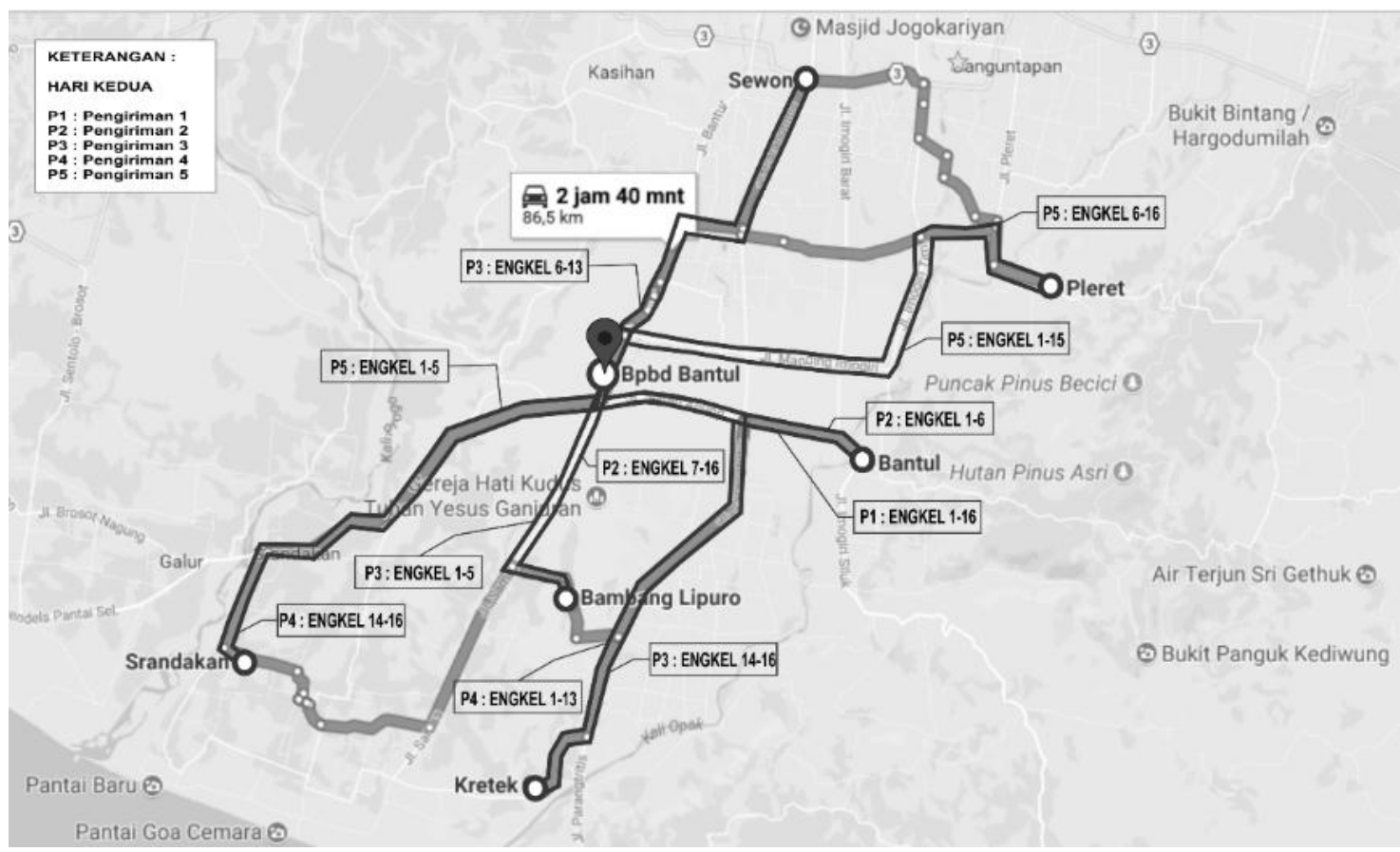

Gambar 2. Rute pengiriman dengan truk engkel hari 2 


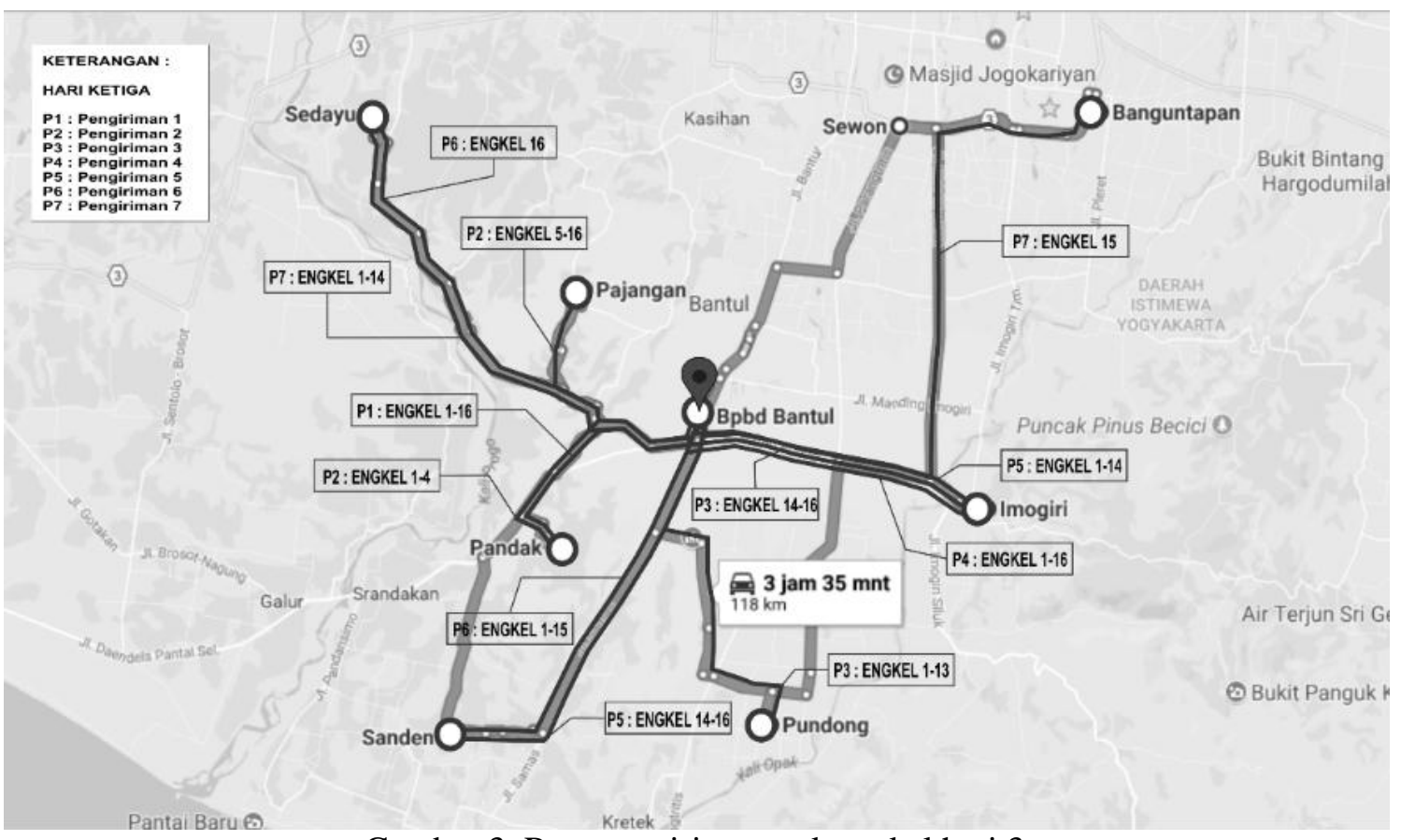

Gambar 3. Rute pengiriman truk engkel hari 3

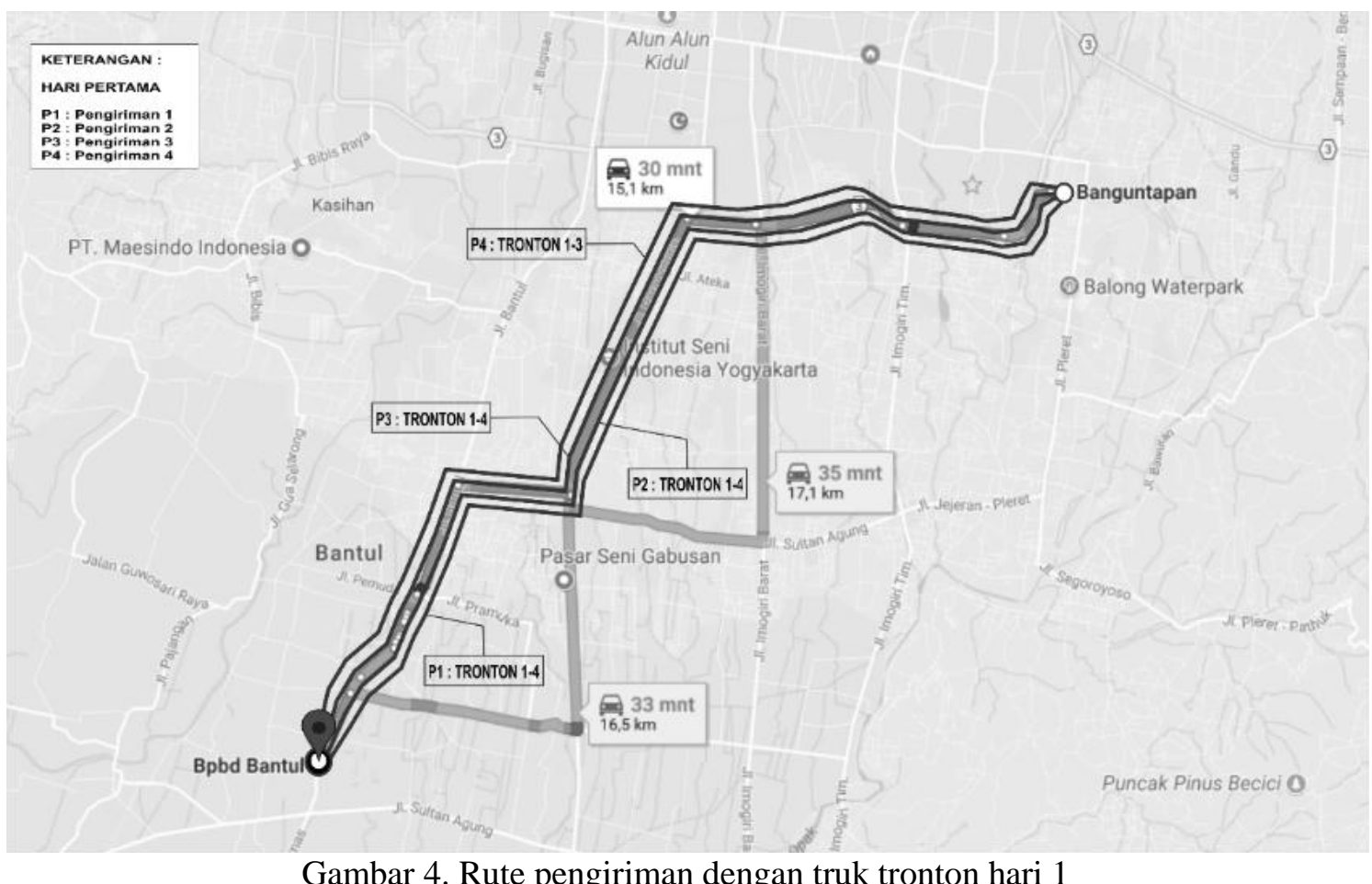

Gambar 4. Rute pengiriman dengan truk tronton hari 1 


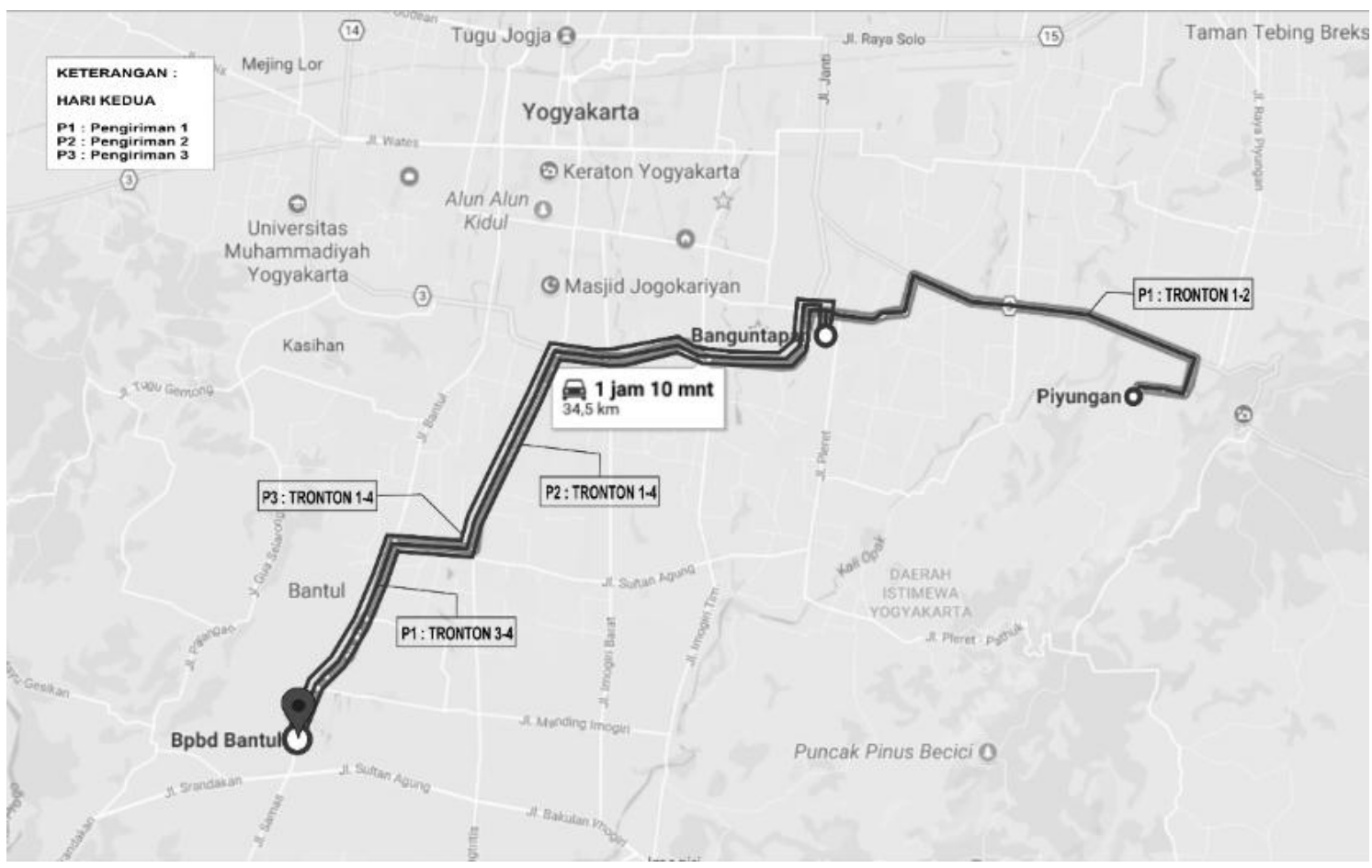

Gambar 5. Rute pengiriman dengan truk tronton hari 2

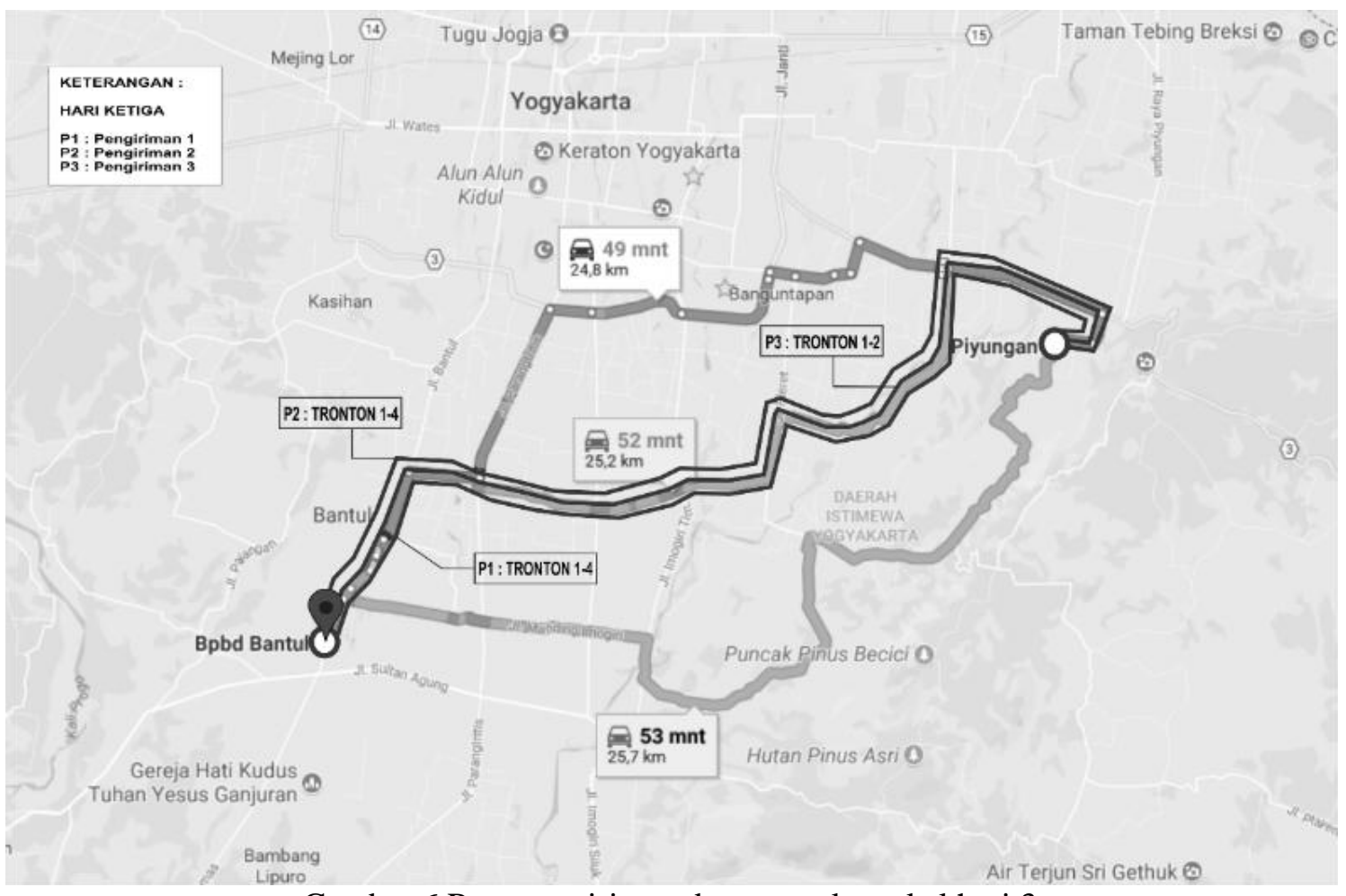

Gambar 6 Rute pengiriman dengan truk engkel hari 3

Dengan mempertimbangkan jarak tempuh, waktu perjalanan, waktu bongkar muat dan kondisi topografi pada masing-masing tujuan, selanjutnya dapat ditentukan waktu yang diperlukan untuk perjalanan dan bongkar muat dari masing-masing kendaraan seperti Tabel 2. 
Tabel 2. Waktu pengiriman per hari

\begin{tabular}{lrrrrrrr}
\hline \multicolumn{1}{c}{ Truk } & Hari 1 & Hari 2 & Hari 3 & Truk & Hari 1 & Hari 2 & Hari 3 \\
\hline Engkel 1 & 11,26 & 11,26 & 12,91 & Engkel 11 & 11,33 & 11,33 & 13,10 \\
Engkel 2 & 11,26 & 11,26 & 12,91 & Engkel 12 & 11,33 & 11,33 & 13,10 \\
Engkel 3 & 11,26 & 11,26 & 12,91 & Engkel 13 & 11,33 & 11,33 & 13,10 \\
Engkel 4 & 11,26 & 11,26 & 12,91 & Engkel 14 & 11,33 & 11,33 & 13,11 \\
Engkel 5 & 11,26 & 11,26 & 13,10 & Engkel 15 & 11,33 & 11,33 & 13,29 \\
Engkel 6 & 11,26 & 11,26 & 13,10 & Engkel 16 & 9,30 & 9,30 & 11,26 \\
Engkel 7 & 11,26 & 11,26 & 13,10 & Tronton 1 & 9,34 & 9,34 & 8,17 \\
Engkel 8 & 11,33 & 11,33 & 13,10 & Tronton 2 & 9,34 & 9,34 & 8,17 \\
Engkel 9 & 11,33 & 11,33 & 13,10 & Tronton 3 & 9,34 & 9,34 & 5,44 \\
Engkel 10 & 11,33 & 11,33 & 13,10 & Tronton 4 & 7,01 & 7,01 & 5,44 \\
\hline Total Hari 1 & & & & $\mathbf{2 1 3 , 8 4}$ & \\
\hline Total Hari 2 & & & & $\mathbf{2 0 9 , 4 3}$ & \\
\hline Total Hari 3 & & & & $\mathbf{2 3 4 , 3 7}$ & \\
\hline
\end{tabular}

Berdasarkan perhitungan tersebut, distribusi paket bantuan dari BPBD kabupaten Bantul menuju gudang penyalur yang berada di 17 wilayah kecamatan dapat dilakukan selama 3 hari dengan total waktu pengiriman 213,84 jam, dengan melibatkan 16 truk engkel dan 4 truk tronton yang dimiliki SKPD Kabupaten Bantul, TNI dan Polri.

\section{SIMPULAN}

Berdasarkan pengembangan model dengan skenario jumlah pengungsi $80 \%$ dari populasi pada daerah sangat rawan, $60 \%$ pada daerah rawan, dan $40 \%$ pada daerah kurang rawan didapatkan model matematis distribusi alokasi yang diselesaikan dengan Linear Programming. Solusi optimal menunjukkan hasil bahwa dibutuhkan distribusi bantuan pada hari pertama sebanyak 60.500 unit, pada hari kedua sebanyak 59.500 unit dan pada hari ketiga sebanyak 60.500 unit. Selanjutnya berdasarkan penentuan rute pengiriman menggunakan Nearest Neighbors Algorithm didapatkan rute pengiriman untuk 16 truk engkel dan 4 truk tronton yang dilibatkan dalam proses distribusi bantuan. Kebutuhan waktu pengiriman untuk hari pertama adalah 213,84 jam, hari kedua sebesar 209,43 jam dan hari ketiga sebesar 234,37 jam.

\section{UCAPAN TERIMA KASIH}

Penulis mengucapkan terimakasih kepada Kopertis Wilayah V yang telah memberikan dukungan finansial melalui Bantuan Dana Penelitian DIPA Kopertis V Yogyakarta tahun 2017.

\section{DAFTAR PUSTAKA}

Akhbari, M., Mehrjerdi, Y. Z, Zare, H. Z, Makui, A. (2014). A Novel Continuous Knn Prediction Algorithm to Improve Manufacturing Policies in A VMI Supply Chain. International Journal of Engineering, Transactions B: Applications, 27(11), 1681-1690.

Alonso, F., Alvarez, M. J., Beasley, J.E. (2008). A Tabu Search Algorithm for The Periodic Vehicle Routing Problem with Multiple Vehicle Trips and Accessibility Restrictions. Journal of the Operational Research Society, 59(7), 963-976.

Boonsam, P., Suthikarnnarunai, N., dan Rattanawong, W. (2013). Efficiency Improvement for Multi Depot Vehicle Routing: A Case Study in Cash Distribution. Applied Mechanic and Materials, 284-287, 3667-3674.

Braysy, O., Gendreu, M. (2005), Vehicle Routing Problem with Time Windows, Part I: Route Construction and Local Search Algorithms, Transportation Science, Vol 39, No. 1, Hal 104-118. 
Cahya, C. T. (2013). Perancangan Algoritma Tabu Search Untuk Vehicle Routing Problem With Time Windows Di Distributor PT. Intermas Tata Trading, Journal Logistics and Supply Chain Management. 3(3), 171-180.

Cooper, M. C., Lambert, D. M., dan Pagh, J. (1997). Supply Chain Management: More Than a New Name for Logistics. The International Journal of Logistics Management, 8(1), 1-14.

El-Sherbeny, N. (2010). Vehicle routing with time windows: An overview of exact, heuristic and metaheuristic methods. Journal of King Saud University - Science, 22(3), 123-131.

Kritikos, M.N, dan Ioannou. G. (2010). The Balanced Cargo Vehicle Routing Problem with Time Windows. International Journal of Production Economics, 123(1), 42-51.

Liu, Chun-Ying. (2013), An Improved Adaptive Genetic Algorithm for the Multi-depot Vehicle Routing Problem with Time Window, Journal of Network, 8(5), 1035-1042

Mukhsinin, A. Imran, A., Susanty, S. (2013). Penentuan Rute Distribusi CV. IFFA Menggunakan Metode Nearest Neighbour dan Local Search. Jurnal Reka Integra, 2(2), 129 -138 .

Nugroho, Y. A., Haryanto, D., dan Lucitasari, D. R. (2016). Model Distribusi Logistik Kemanusiaan Dalam Menghadapi Bencana Gempa Bumi Di Kabupaten Bantul. Jurnal Disprotek, 7(2), 43 - 52.

Palit dan Sherly, 2012, Vehicle Routing Problem With Time Windows Pada Distributor Bahan Makanan, Prosiding Seminar Nasional Manajemen Teknologi XV

Shenoy, U.V. (2012). Enhanced Nearest Neighbors Algorithm s Algorithm for Design of water Network. Chemical Engineering Science. 84, 197-206.

Sheu, J. B. (2007). Challenges of emergency logistics management. Transportation Research Part E: Logistics and Transportation Review. 43(6), 655-772.

Suhaibah, A., Uznir, U., Anton, F., Mioc, D., Rahman, A. A. (2016). 3D Nearest Neighbour Search Using a Clustered Hierarchical Tree Structure, The International Archives ISPRS Congress, Prague, XLI-B2, 82 - 93.

Susetiono. (2010). Laporan Akhir Program Insentif Peneliti dan Perekayasa LIPI Tahun 2010 : Sistem Pengelolaan Pemenuhan Kebutuhan Dasar Korban Bencana Alam, Pusat Penelitian Oseanografi LIPI, Jakarta.

Timoleon. (2012). The Logistics Chain of Emergency Supplies in Disasters, Master Course, Athens: Athens University. 